Research Article

\title{
Five-Echelon Multiobjective Health Services Supply Chain Modeling under Disruption
}

\author{
Farnaz Javadi Gargari, ${ }^{1}$ Mahjoube Sayad, ${ }^{1}$ Seyed Ali Posht Mashhadi, ${ }^{2}$ \\ Abdolhossein Sadrnia $\mathbb{D}^{\mathrm{D}}{ }^{3}$ Arman Nedjati, ${ }^{3}$ and Tahereh Yousefi Golafshani ${ }^{4}$ \\ ${ }^{1}$ Department of Industrial Engineering, Alzahra University, Tehran, Iran \\ ${ }^{2}$ Department of Industrial Engineering, Islamic Azad University, South Tehran Branch, Iran \\ ${ }^{3}$ Assistant Professor of Department of Industrial Engineering, Quchan University of Technology, P.O. Box: 94771-67335, Quchan, \\ Iran \\ ${ }^{4}$ Almahdi Aluminum Co, Hormozgan Province, Bandar Abbas, Iran
}

Correspondence should be addressed to Abdolhossein Sadrnia; a.sadrnia@qiet.ac.ir

Received 18 March 2021; Revised 19 April 2021; Accepted 25 April 2021; Published 19 May 2021

Academic Editor: Mohammad Yazdi

Copyright @ 2021 Farnaz Javadi Gargari et al. This is an open access article distributed under the Creative Commons Attribution License, which permits unrestricted use, distribution, and reproduction in any medium, provided the original work is properly cited.

\begin{abstract}
Medicine unreliability problem is taken into consideration as one of the most important issues in health supply chain management. This research is associated with the development of a multiobjective optimization problem for the selection of suppliers and distributors. To achieve the purposes, the optimal quota allocation is determined with respect to disruption of suppliers in a five-echelon supply chain network and consideration of the distributor centers as a hub location-allocation mode. The objective of the optimization model is involved in simultaneous minimization of transactions costs dealing with suppliers, expected purchasing costs from suppliers, expected percentages of delayed and returned products in each distributor, as well as transportation cost in each echelon and fixed cost for distributor centers, and finally maximization of the expected scores for suppliers and high priority of product customers. The optimization problem is formulated as a mixed-integer nonlinear programming model. The proposed optimization model is utilized to investigate a numerical case study for asthma-specific medicines. The analyzing procedure is conducted based on the collected real data from Cobel Darou pharmaceutical company in 2019. Furthermore, a fuzzy multichoice goal programming model is considered to solve the proposed optimization model by $R$ optimization solver. The numerical results confirmed the authenticity of the model.
\end{abstract}

\section{Introduction}

Nowadays, engineering and science advances have contributed to the significant reduction of incurable disease and infant mortality in human societies. It occurred due to the classification of the issue of health and treatment as one of the most important multidisciplinary topics in human societies. However, healthcare costs have had a rising trend, and thus, controlling and mitigating of costs of health systems make considerable concerns in this domain [1]. Therefore, scholars and researchers and also governments attempt to reduce the rate of healthcare costs by monitoring these kinds of costs. The health organizations demand reduction of the treatment costs, increment of the quality of health systems, patient safety, as well as improvement and enhancement of the effectiveness, and efficiency through a methodology, which is called the health supply chain.

Many researchers believe that the application of principles of management in the health supply chain, in addition to the decrement of the cost of care and treatment, leads to the improvement of the quality of services $[2,3]$. Nevertheless, potential disturbances have raised risks against supply chains [4]. Healthcare area has suffered continuous challenges over decades [5]. To deal with this, researchers and practitioners have focused on devise and implementation of various practices [6]. The major challenges for 
the pharmaceutical supply chain include lack of coordination, inventory management, human resource dependency, absent demand information, order management, shortage avoidance, warehouse management, expiration, shipment visibility, and temperature control [7]. One of the challenges of this field is the disorder of medicine distribution that leads to medicine deficiencies. Inadequate distribution and medicine and equipment deficiencies disrupt suppliers so that they cannot supply the demand for distribution centers and hospitals in time. Thereby, the overall efficiency of the system and responsibility reduces significantly. The origin of such disorders may be either in transportation systems or in supplier centers themselves, which includes price fluctuations, demand fluctuations, equipment failure, and quality failure [8]. Moreover, natural disasters, equipment failures, terrorist attacks, labor strikes, and change in property could be the reason for such disorders [9]. In reality, the cases that include such disorders are summarized as follows: (1) the tragic earthquake in Bam caused severe damage to the infrastructure, underground, and transport systems [10], (2) Hurricane Katrina (2005), which caused the destruction of manufacturing and transportation equipment in the coast of the Persian Gulf [11], (3) the earthquake in Japan (2011) that halted production in a wide range of industries due to the power outage and the blockage of transportation routes [12], and (4) the outbreak of coronavirus in the Wuhan city in the winter of 2020, which caused more than 213 countries (based on https://www.worldometers.info/coronavirus/countrieswhere-coronavirus-has-spread/\%20live $\% 20$ data $\% 20$ in $\%$ 20 the $\% 20$ first $\% 20$ of\%20June $\% 202020$ ) to implement the quarantine, more than policy and disruption to transport systems. Coronavirus outbreak affected more than $6,235,658$ cases and taken the lives of about 373,176 up to the end of May 2020. It should be noted that these statistics relate to the end of March 2020; significantly, infected population numbers and death rates change daily [13]. The earthquake in China (2008), the tornados of the Philippines in 2013, and the Indian Ocean tsunami are also among the natural disasters. Apart from natural disasters, human disasters have also disrupted related organizations. Disasters like the Mumbai attacks in 2011 and the September 11 terrorist attack in the United States are among the human disasters. [14] This shows the importance of logistics network design with high reliability in unfavorable conditions.

The supply chain disruption makes vital impacts on patient level, especially in the shortage of medicines $[15,16]$. The world has witnessed a 300\% increase in new medicine shortages since 2006. Recently, multiple countries and domains have been involved in this problem [15]. The problem posed by the supply chain disruptions puts the pharmaceutical companies under tangible pressure and may also compromise human health by medicine shortages. Inappropriate situations for distribution of medicines, hospital equipment, and their shortage can cause irreparable damage to countries and health systems. However, desirable implementation of the health supply chain management can considerably contribute to the reduction of the total costs in the healthcare sector [17]. Besides, the evolution of the logistics system can lead to the improvement of the distribution of medicines and equipment in this sector. To date, studies have been done on supply chain network design under disruptions in different areas, such as supplier selection and order allocation [18] and blood supply chain [19] by using different quantitative approaches. Accordingly, some of the studies have affected the impact of epidemic outbreaks on supply chains $[20,21]$. Due to two unique features, the disasters caused by disease outbreaks vary from other disasters: their long-term damage and their growing spread. Failure to control such disasters will result in severe disruptions in supply chains and communities and will result in irreparable losses. Coronavirus 2019 (COVID-19) is one of those disasters that has caused severe disease [22]. Also, careful pharmacy management has a strong effect on the capacity of a country to tackle public health issues. Pharmaceutical supply management is one of the most operational problems in the healthcare industries [23].

However, as the relevant literature demonstrates, few studies have been carried out in the field of hierarchical localization, which considers disruption in supply centers within the health services networks. According to the mentioned cases, this paper presents a five-objective hierarchical location for designing health services networks that distribution centers are considered as a hub location-allocation method. In the proposed model, unlike the previous research, we consider several key issues, which help to manage and design health services networks, such as the hierarchical organization of the networks, purchasing a group of medicine, disrupting the tasks of the suppliers, and its effects, which undoubtedly lead to a lack of inventory. Since the model is formulated as a multiobjective function, a fuzzy multiobjective goal programming model is considered to solve the proposed optimization model using the $R$ optimization solver. A practical case study is also presented according to the actual information of Cobel Darou pharmaceutical company to show the application of the proposed model and effectiveness of the designed method.

The rest of this paper is structured as follows. Section 2 comprises a review of the health supply chain literature. In Section 3, the proposed methodology and assumptions are characterized for the problem. Section 4 presents a case study for validation of the represented model. Section 5 is dealt with the development of sensitivity analysis for the model, and the results are displayed by a diagram. Finally, the whole results of this paper are provided in Section 6. The obtained conclusion proves the application of the proposed model in the real world.

\section{Literature Review}

In this section, we examine the relevant literature in two separate but complementary parts in the field of health services networks: hierarchical location-allocation for health networks and facility location problems under disruptions.

2.1. Hierarchical Location-Allocation for Supply Chains of Health Networks. Location-allocation of facilities is the location of a set of facilities to minimize the cost of the 
response to demands. In other words, hierarchical locationallocation models deal with the location of new facilities in specific regions and the assignment of demand nodes to established facilities. Depending on the nature of the system, these models can include single-level or hierarchical networks. Several studies have been carried out in this field. The purpose of the present study is not to investigate all the impacts related to the location-allocation model, but a selection of research studies is presented to review this field comprehensively. The studies carried out for single-level systems include the location-allocation model in the field of health care services with geographical considerations to assess different options for providing services [24], assessing the location of blood banks of the American red cross in the middle region of the Atlantic Ocean [25], the multistage location-allocation model for organ transplant centers [26], and the evaluation of the location models of emergency services using a simulation method [27]. Khodaparasti et al. [28] presented a multiperiod location-allocation model for the home for the aged network to improve access to services. In cases where there is a relationship between facilities at different levels of communication, the system is considered hierarchical. The majority of health care systems have a hierarchical organization, some of which are as follows: due to the weak geographical access in developing countries, Rahman and Smith [29] proposed a hierarchical locationallocation model for scheduling the health services. Hodgson and Jacobsen [30] proposed the concept of "expected distance under referral" for primary health care centers using the P-median hierarchical location-allocation model. Fahimnia et al. [14] investigated a two-objective location of mobile blood donation facilities in a blood supply network, which includes different levels including blood donors, mobile blood donation facilities (blood donation vehicles), local and regional blood donation centers, and hospitals (demand points). In the same year, Mestre et al. [31] presented two hierarchical location-allocation models with a demand under uncertainty to enhance the geographic access while minimizing the costs in the hospital network. Also, Hovav and Tsadikovich [32] proposed a facility location inventory problem to reduce the cost of the influenza vaccination program. Elalouf et al. [33] to reduce operating costs by repairing and maintaining blood sample collection chain have developed a model for facility location problem solving and proposed the dynamic programming (DP) algorithm and fully polynomial time approximation scheme (FPTAS) algorithm to solve it. Chaiwuttisak et al. [34] proposed a binary integer programming model for locationallocation problem in two-level based on goals of improving blood supply while reducing transport costs. Safaei et al. [35] proposed a location-allocation model for pharmacies in Chalus city according to the Group Purchase Organization (GPO) which is the proposed multiobjective model that was optimized using goal programming. Wang et al. [36] proposed a hierarchical location-allocation model to describe trade between social, economic, and environmental factors in health networks from the supply and demand perspective. Then, they solved the model by a bilevel multiobjective particle swarm optimization algorithm. Finally, Barzinpour et al. [37] proposed a hierarchical location-allocation model for health network design considering the referral system.

2.2. Facility Location Problems under Disruptions. In this section, primarily, we report a brief history of disruption in the systems and supply chain. Afterward, we review the studies that have been carried out in the field of health care. In the last decade, the problems under the disruption have been considered by many researchers. Drezner [38] conducted the first study of Two Location Problems with Unreliable Facilities and defined the P-Median and (p, q) problems by assuming that the facilities may be inactive. On the other hand, supply chain disruption orientation (SCDO) concept is considered as the first systematic empirical investigation for organizational responses to the disruptions of the supply chain, which was introduced by [39]. It is essential to carry out some research studies about various aspects of supply chain disruption such as strategic management $[40,41]$, strategic (resilience) management [42, 43], and risk management $[44,45]$. The supply chain is highly affected by information flow, as well as goods and financial resource flows, and thus it is necessary to integrate these items to decline the vulnerabilities [46]. Another research by Cui et al. [47] and Shen et al. [48], which considered the stochastic scenario-based formulations, also has investigated the supply chain disruption. Furthermore, Peng et al. [12] decreased the risk of disruption for a logistics network under facility failure using p-robust. To solve the problem, a hybrid metaheuristic algorithm was employed based on genetic algorithms, local improvement, and the shortest pathway. Shishebori and Yousefi Babadi [49] addressed the designing problem of a robust and reliable medical service (MS) center location network by considering the disruption in the system and constraint on investment budget and p-robust constraints. At this time, An et al. [50] have designed an article to address potential risks and disruptions in emergency service planning that including the facility disruption risks, congestion in road traffic, and queuing delays in facilities. A scenario-based stochastic mixed-integer nonlinear program (MINLP) used the Lagrangian relaxation approach to solve. Zarrinpoor et al. [51] designed the reliable hierarchical location-allocation model for medical service networks in which they considered disruption in the facilities. To ensure the quality of services and demand, they added the queuing systems to their model. Finally, the model is formulated based on the two-stage optimization approach, and decision making is defined in two stages. To minimize the cost and time of emergency delivery of products to customers after a disaster, a biobjective robust optimization model has been designed with considering possible disruptions in facilities and routes and a Lagrangian relaxation and $\varepsilon$-constraint to solving the approach have been proposed [52]. To reduce greenhouse gas emissions in the biofuel supply chain network, Fattahi and Govindan [53] proposed a cost-effective multistep random program to show the impact of disruption risk dimensions and sustainability dimensions on biofuels. To reduce potential risks and disruptions in supply chain design, Sabouhi et al. [9] have provided an integrated 
approach based on data envelopment analysis (DEA) and mathematical planning methods. First, the efficiency of potential suppliers is determined by fuzzy DEA, and then a two-stage possibilistic-stochastic programming model is created to select a supplier, and the results are examined in a pharmaceutical company for the application of the presented model. In the health supply chain section, Haghjoo et al. [54] proposed a dynamic robust location-allocation model to solve the disruption in the blood supply to hospitals and designed a scenario-based robust approach for the inherent uncertainty of the problem. Besides, to solve the large-scale problems, they proposed two metaheuristic algorithms, namely, the self-adaptive imperialist competitive and invasive weed optimization. In this regard, Hamdan and Diabat [19] designed a biobjective robust optimization model for the medical blood supply chain with considering disruption in the facilities. A Lagrangian relaxation-based algorithm is developed for solving large-scale instances. Table 1 shows how the proposed model covers all of these. The coding of columns of the problem type in Table 1 is also defined in Table 2.

According to Table 1, most of the research papers presented in the health supply chain section consider the model as a single level, and also, no research in the literature uses different aspects of capacity constraint, multiperiod, and hub simultaneously.

\section{Problem Description}

This paper is focused on a five-echelon multiobjective optimization program for the selection of suppliers and distributors. In this regard, the optimal quota allocation is determined with respect to disruption of suppliers and consideration of the distributor centers as a hub locationallocation mode. The relationships between the five echelons in the model are shown in Figure 1.
In this study, the proposed objective functions are characterized as follows: minimization of transactions costs with suppliers, minimization of expected purchasing costs from suppliers, minimization of expected percentages of delayed goods and returned goods in each distributor, as well as transportation cost in each echelon and fixed cost for distributor centers, and finally maximization of the expected scores for suppliers and total priority of product for customers.

The number of two suppliers is generally selected for each hub-center distributor. The second supplier is designated as the backup supplier for the first selected center. If the demand is not supplied by the first center because of disruption, the backup supplier will be allocated 100 percent of the quota.

Assumptions of the problem are denoted as follows:

Suppliers may be nonaccessible because of disruption Delay in providing each quota is allowed

It is allowed to return the product to distributors by customers or other distributors

The problem is investigated in multiple periods

Each quota can be allocated to the second supplier for supporting the nonprovided demands, which cannot be supplied by the first supplier

Only one center is selected in each level of the distribution

3.1. Mathematical Model. This section is developed to address the proposed mathematical model for the problem. To do this, the mathematical model is given in equations (1)-(40). Table 3 represents the required notations for the models.

The objective functions are as follows:

$$
\begin{aligned}
& \operatorname{Min} z 1: \sum_{k} \sum_{j} \sum_{p} \sum_{t}\left(Q_{k j p t} C_{k j p t} Y_{k j t}\left(1-R_{k}\right)+R_{k} Q_{k j p t}+\sum_{k} \sum_{j} \sum_{p} \sum_{t} C_{k j p t} Y_{k j t}\right) \\
& \quad+\sum_{j} F_{j} X_{j}+\sum_{h} F_{h} X_{h}+\sum_{n} F_{n} X_{n}+\sum_{k} \sum_{j} \sum_{p} \sum_{t} T S_{k j p t}\left(L_{k j}\right) Y_{k j t}\left(Q_{k j p t}\right)\left(1-R_{k}\right)+R_{k} Q_{k j p t} \\
& \sum_{k} \sum_{j} \sum_{p} \sum_{t} T S_{k j p t}\left(L_{k j}\right) Y_{k j t}+ \\
& k \neq k \\
& \sum_{j} \sum_{h} \sum_{p} \sum_{t} T S_{j h p t}\left(L_{j h}\right) \beta Y_{k j t} Q_{j h p t}+\sum_{h} \sum_{n} \sum_{p} \sum_{t} T S_{h n p t}\left(L_{h n}\right) Y_{j h t} Q_{h n p t}+\sum_{n} \sum_{i} \sum_{p} \sum_{t} T S_{n i p t}\left(L_{n i}\right) Y_{n i t} Q_{n i p t}, \\
& \operatorname{Min} Z_{2}: \sum_{k} \sum_{j} \sum_{p} \sum_{t} \alpha_{k p t} C C_{k j p t} Y_{k j t},
\end{aligned}
$$

$\operatorname{Min} Z_{3}: \sum_{j} \sum_{h} \sum_{p} \sum_{t} h_{j p t} Q_{j h p t} Y_{j h t}+\sum_{h} \sum_{n} \sum_{p} \sum_{t} h_{h p t} Q_{h n p t} Y_{h n t}+\sum_{n} \sum_{i} \sum_{p} \sum_{t} h_{n p t} Q_{n i p t} Y_{n i t}$, 
TABLE 1: Classification of the related papers.

\begin{tabular}{|c|c|c|c|c|c|c|c|c|c|c|}
\hline \multirow[b]{2}{*}{ Articles } & \multirow{2}{*}{$\begin{array}{l}\text { Problem } \\
\text { Type }\end{array}$} & \multirow{2}{*}{$\begin{array}{l}\text { Health } \\
\text { supply } \\
\text { chain }\end{array}$} & \multirow{2}{*}{$\begin{array}{c}\text { System } \\
\text { disruption }\end{array}$} & \multicolumn{2}{|c|}{ Network structure } & \multicolumn{3}{|c|}{ Model features } & \multirow[b]{2}{*}{ Solution method } & \multirow{2}{*}{$\begin{array}{l}\text { Case } \\
\text { study }\end{array}$} \\
\hline & & & & $\begin{array}{c}\text { Single } \\
\text { level }\end{array}$ & Hierarchical & Hub & Multiperiod & Capacity & & \\
\hline Jacobs et al. [25] & FLP & $\checkmark$ & & $\checkmark$ & & & & & Scenario base & $\checkmark$ \\
\hline Zahiri et al. [26] & FLAP & $\checkmark$ & & $\checkmark$ & & & $\checkmark$ & & $\begin{array}{l}\text { Robust possibilistic } \\
\text { programming and } \\
\text { GAMS }\end{array}$ & $\checkmark$ \\
\hline $\begin{array}{l}\text { Ünlüyurt and } \\
\text { Tunçer. [27] }\end{array}$ & MCLP & $\checkmark$ & & $\checkmark$ & & & & & CPLEX & $\checkmark$ \\
\hline $\begin{array}{l}\text { Khodaparasti } \\
\text { et al. [28] }\end{array}$ & LAP & $\checkmark$ & & $\checkmark$ & & & $\checkmark$ & $\checkmark$ & $\begin{array}{l}\text { Outer approximation } \\
\text { algorithm (AOA) }\end{array}$ & $\checkmark$ \\
\hline $\begin{array}{l}\text { Hodgson and } \\
\text { Jacobsen. [30] }\end{array}$ & MHLAP & $\checkmark$ & & & $\checkmark$ & & & & CPLEX & \\
\hline $\begin{array}{l}\text { Fahimnia et al. } \\
{[14]}\end{array}$ & FLP & $\checkmark$ & & & $\checkmark$ & & $\checkmark$ & $\checkmark$ & $\begin{array}{c}\varepsilon \text {-constraint and } \\
\text { Lagrangian relaxation } \\
\text { and GAMS }\end{array}$ & \\
\hline Mestre et al. [31] & MHLAP & $\checkmark$ & & & $\checkmark$ & & $\checkmark$ & $\checkmark$ & $\begin{array}{c}\mathcal{\varepsilon} \text {-constraint and } \\
\text { CPLEX }\end{array}$ & $\checkmark$ \\
\hline $\begin{array}{l}\text { Hovav and } \\
\text { Tsadikovic [32] }\end{array}$ & FLIP & $\checkmark$ & & & $\checkmark$ & & $\checkmark$ & $\checkmark$ & Heuristic algorithm & $\checkmark$ \\
\hline $\begin{array}{l}\text { Elalouf et al. } \\
\text { [33] }\end{array}$ & FLP & $\checkmark$ & & & $\checkmark$ & & & & $\begin{array}{l}\text { DP algorithm and } \\
\text { FPTAS algorithm }\end{array}$ & $\checkmark$ \\
\hline $\begin{array}{l}\text { Chaiwuttisak } \\
\text { et al. [34] }\end{array}$ & FLAP & $\checkmark$ & & & $\checkmark$ & & & $\checkmark$ & CPLEX & $\checkmark$ \\
\hline Safaei et al. [35] & HGPP & $\checkmark$ & & & $\checkmark$ & & & & $\begin{array}{c}\text { Weighted goal } \\
\text { programming (WGP) } \\
\text { and Lingo }\end{array}$ & $\checkmark$ \\
\hline Li et al. (2018) & HFLAP & $\checkmark$ & & & $\checkmark$ & & & & $\begin{array}{c}\text { (BLMOPSO) } \\
\text { algorithm }\end{array}$ & $\checkmark$ \\
\hline $\begin{array}{l}\text { Barzinpour et al. } \\
\text { [37] }\end{array}$ & HLAP & $\checkmark$ & & & $\checkmark$ & & & $\checkmark$ & $\varepsilon$-constraint & \\
\hline Drezner [38] & PQCP & & $\checkmark$ & $\checkmark$ & & & & & Heuristic algorithm & \\
\hline Cui et al. [47] & UFLP & & $\checkmark$ & $\checkmark$ & & & & & Lagrangian relaxation & \\
\hline Shen et al. [48] & UFLP & & $\checkmark$ & $\checkmark$ & & & & & $\begin{array}{l}\text { Approximation } \\
\text { algorithm }\end{array}$ & $\checkmark$ \\
\hline $\begin{array}{l}\text { Peng et al. [12] } \\
\text { Shishebori and }\end{array}$ & LNDP & & $\checkmark$ & $\checkmark$ & & & & $\checkmark$ & Genetic algorithm & \\
\hline $\begin{array}{l}\text { Yousefi Babadi } \\
\text { [49] }\end{array}$ & FL/NDP & $\checkmark$ & $\checkmark$ & $\checkmark$ & & & & $\checkmark$ & CPLEX & $\checkmark$ \\
\hline An et al. [50] & FLP & & $\checkmark$ & $\checkmark$ & & & & & Lagrangian relaxation & $\checkmark$ \\
\hline $\begin{array}{l}\text { Zarrinpoor et al. } \\
\text { [51] }\end{array}$ & MHLAP & $\checkmark$ & $\checkmark$ & & $\checkmark$ & & & $\checkmark$ & $\begin{array}{c}\text { Benders } \\
\text { decomposition (BD) }\end{array}$ & $\checkmark$ \\
\hline Diabat et al. [52] & HFLAP & & $\checkmark$ & & $\checkmark$ & & $\checkmark$ & $\checkmark$ & $\begin{array}{l}\text { Lagrangian relaxation } \\
\text { and } \varepsilon \text {-constraint }\end{array}$ & $\checkmark$ \\
\hline $\begin{array}{l}\text { Fattahia and } \\
\text { Govindan [53] }\end{array}$ & FLP & & $\checkmark$ & & $\checkmark$ & & $\checkmark$ & $\checkmark$ & $\begin{array}{l}\text { Rolling horizon } \\
\text { procedure }\end{array}$ & $\checkmark$ \\
\hline Sabouhi et al. [9] & LIP & $\checkmark$ & $\checkmark$ & & $\checkmark$ & & & $\checkmark$ & Fuzzy DEA & $\checkmark$ \\
\hline $\begin{array}{l}\text { Haghjoo et al. } \\
\text { [54] }\end{array}$ & DRLAP & $\checkmark$ & $\checkmark$ & $\checkmark$ & & & $\checkmark$ & $\checkmark$ & $\begin{array}{l}\text { Robust optimization } \\
\text { and two metaheuristic }\end{array}$ & $\checkmark$ \\
\hline $\begin{array}{l}\text { Hamdan and } \\
\text { Diabat. [19] }\end{array}$ & HFLAP & $\checkmark$ & $\checkmark$ & & $\checkmark$ & & $\checkmark$ & $\checkmark$ & Lagrangian relaxation & $\checkmark$ \\
\hline Current study & HHLAP & $\checkmark$ & $\checkmark$ & & $\checkmark$ & $\checkmark$ & $\checkmark$ & $\checkmark$ & $\begin{array}{l}\text { Fuzzy multichoice } \\
\text { goal programming } \\
\text { model and } R \text { solver }\end{array}$ & $\checkmark$ \\
\hline
\end{tabular}


Table 2: Coding of problem type in Table 1.

\section{Problem type}

Facility location problem

Facility location inventory problem

FLIP

Maximal coverage location problem

MCLP

Hierarchical group purchasing problem

HGPP

Hierarchical location-allocation problem

HLAP

Logistic network design problem

LNDP

Median hierarchical location-allocation problem

MHLAP

Hierarchical hub location-allocation problem

HHLAP

Location-allocation problem

LAP

Location inventory problem

LIP

Facility location-allocation problem

FLAP

Hierarchical facility location-allocation problem

HFLAP

(p, q)-center problem

PQCP

Facility location/network design problem

FL/NDP

Dynamic robust location-allocation problem

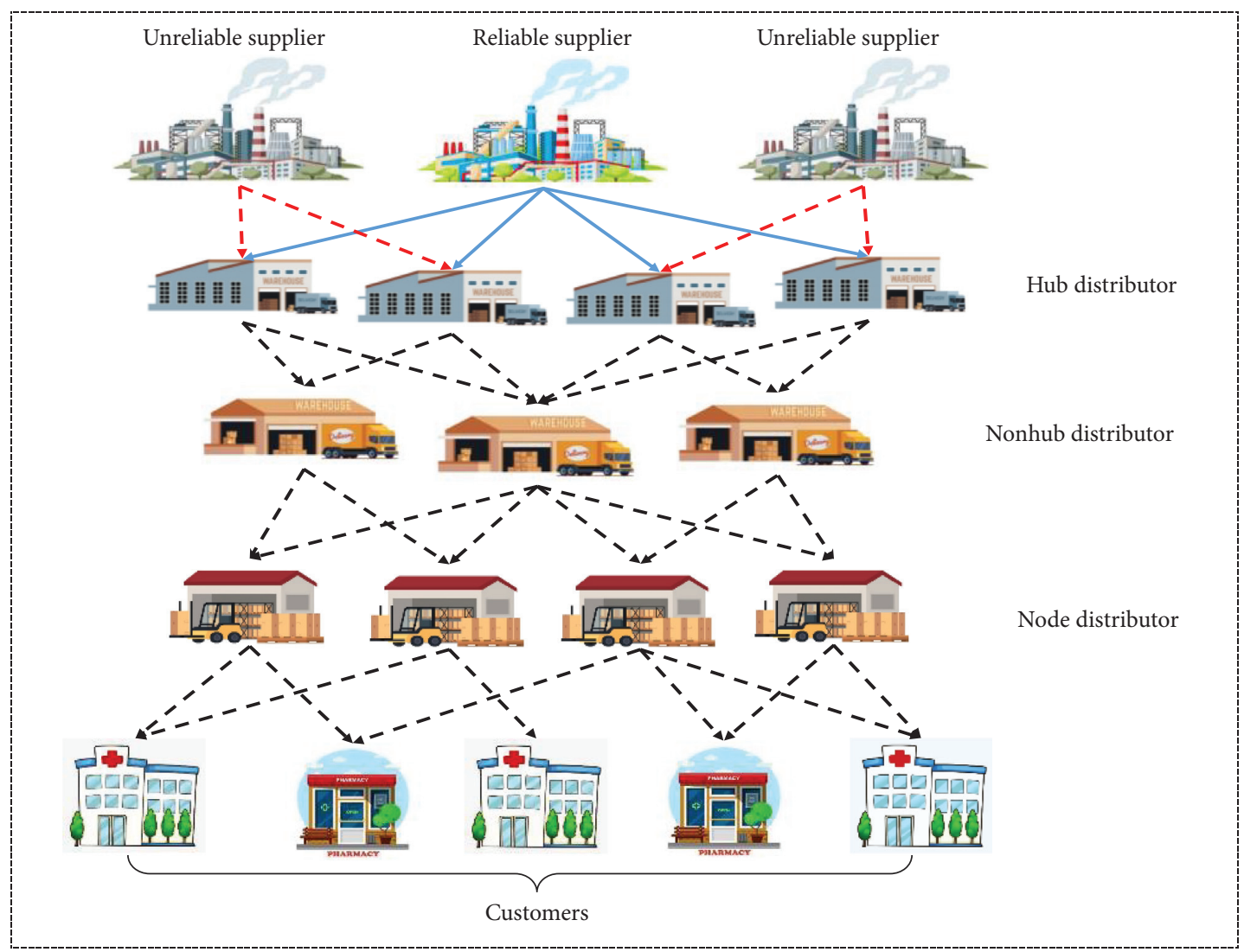

Backup connections

$--\rightarrow$ Connections

Figure 1: General view of the problem.

$\operatorname{Min} Z_{4}: \sum_{j} \sum_{h} \sum_{p} \sum_{t} s_{j p t} Q_{j h p t} Y_{j h t}+\sum_{h} \sum_{n} \sum_{p} \sum_{t} s_{h p t} Q_{h n p t} Y_{h n t}+\sum_{n} \sum_{i} \sum_{p} \sum_{t} s_{n p t} Q_{n i p t} Y_{n i t}$,

$\operatorname{Max} Z_{5}: \sum_{k} \sum_{j} \sum_{t} q_{k} Y_{k j t}$ 
TABle 3: Notations.

$\mathrm{C}_{\mathrm{kjpt}}$ : unit purchasing price of product $p$ given by supplier $k$ to hub distributor $j$ at period $t$

$\mathbf{C C}_{\text {kjpt }}$ : transaction costs of providing product $p$ via supplier $k$ to hub distributor $j$ at period $t$

$\mathrm{TS}_{\mathrm{kjpt}}$ : unit transportation price of product $p$ from supplier $k$ to hub distributor $j$ at period $t$

TS $_{\text {jhpt }}$ : unit transportation price of product $p$ from hub distributor $j$ to nonhub distributor $h$ at period $t$

$\mathrm{TS}_{\mathrm{hnpt}}$ : unit transportation price of product $p$ from nonhub distributer $h$ to node distributor $n$ at period $t$

$\beta$ : rate of discount for the transference of products from hub distributors to nonhub distributors

$\alpha_{\text {kpt }}$ : binary parameter (equal to one if product $p$ can be supplied by supplier $k$ at period $t$; otherwise, zero)

$h_{j p t}$ : percentage of returned product $p$ to hub distributor $j$ at period $t$

$h_{h p t}$ : percentage of returned product $p$ to nonhub distributor $h$ at period $t$

$h_{n p t}$ : percentage of returned product $p$ to node distributor $n$ at period $t$

$s_{j p t}$ : percentage of late delivered product $p$ by hub distributor $j$ at period $t$

$s_{h p t}$ : percentage of late delivered product $p$ by nonhub distributor $h$ at period $t$

$s_{n p t}$ : percentage of late delivered product $p$ by node distributor $n$ at period $t$

$L_{j h}$ : distance from hub distributor $j$ to nonhub distributor $h$

$L_{h n}$ : distance from nonhub distributor $h$ to node distributor $n$

$\mathbf{Y}_{\mathrm{kjt}}$ : binary parameter (equal to one if the trade from supplier $k$ to hub distributor $j$ at period $t$ is set; otherwise, zero)

$\mathbf{Y}_{\mathrm{jht}}$ : binary parameter (equal to one if the trade from hub distributor $j$ to nonhub distributor $h$ at period $t$ is set; otherwise, zero)

$\mathbf{Y}_{\mathrm{hnt}}$ : binary parameter (equal to one if the trade from nonhub distributor $h$ to node distributor $n$ at period $t$ is set; otherwise, zero)

$\mathbf{Y}_{\text {nit }}$ : binary parameter (equal to one if the trade from node distributor $n$ to customer $i$ at period $t$ is set; otherwise, zero)

$\mathbf{X}_{\mathbf{j}}$ : binary parameter (equal to one if the hub distributor $j$ is established; otherwise, zero)

$Q_{k j p t}$ : optimal order of product $p$ from supplier $k$ to hub distributor $j$ at period $t$

$Q_{j h p t}$ : optimal order of product $p$ from hub distributor $j$ to nonhub distributor $h$ at period $t$

$Q_{h n p t}$ : optimal order of product $p$ from nonhub distributor $h$ to node distributor $n$ at period $t$

$Q_{\text {nipt }}$ : optimal order of product $p$ from node distributor $n$ to customer $i$ at period $t$

$X_{h}$ : binary parameter (equal to one if the nonhub distributor $h$ is established; otherwise, zero)

$$
\operatorname{Max} Z_{6}: \sum_{n} \sum_{i} \sum_{p} \sum_{t} \lambda_{n p t} Q_{n i p t} Y_{n i t}
$$

Equation (1) gives the first objective function, which is developed to minimize the total purchase cost from suppliers considering disruption of them, also the total fixed cost of distributors, and total transportation cost. Equation (2) characterizes the second objective function. It minimizes the total transaction cost of products between suppliers and hub distributors. The transaction cost is comprised of those fixed costs for the establishment of relations and cooperation with suppliers such as supplier selection, negotiations for contracting, an inspection of goods, and quality control. Equation (3) denotes the third objective function. This function is aimed to minimize the expected total percentages of the returned products. This type of cost will occur if each distributor has not the ability to supply the next level of distributor or customer demand with the expected quality. Equation (4) represents the fourth objective function. It minimizes the expected total percentage of the late delivered products. The fifth objective function is developed in equation (5). This objective function maximizes the expected scores for the selected suppliers based on a conducted periodical evaluation. Equation (6) describes the sixth objective function. This function leads to maximize the priority of the supplied products for customers.

The constraints are formulated for the optimization model as the following equations:

$$
\sum_{k} \sum_{p}\left(Q_{k j p t} Y_{k j t}\left(1-R_{k}\right)+Q_{k j p t}\left(R_{k}\right) \sum_{k} Y_{k j t}\right) \leq W_{j} \quad \forall j, t
$$

$$
\begin{aligned}
& \sum_{j} \sum_{p} Q_{j h p t} Y_{j h t} \leq W_{h} \quad \forall h, t, \\
& \sum_{h} \sum_{p} Q_{h n p t} Y_{h n t} \leq W_{n} \quad \forall n, t, \\
& \sum_{n} Q_{n i p t} Y_{n i t} \leq D_{i p t} \quad \forall i, p, t,
\end{aligned}
$$$$
\sum_{h} Q_{j h p t} Y_{j h t} \leq \sum_{k} Q_{k j p t} Y_{k j t} \quad \forall j, p, t
$$

$\sum_{n} Q_{h n p t} Y_{h n t} \leq \sum_{j} Q_{j h p t} Y_{j h t}, \quad \forall h, p, t$,

$\sum_{i} Q_{n i p t} Y_{n i t} \leq \sum_{h} Q_{h n p t} Y_{h n t}, \quad \forall n, p, t$

$$
\sum_{h} \sum_{t} h_{j p t} Q_{j h p t} Y_{j h t} \leq H_{j p} \quad \forall j, p
$$




$$
\begin{gathered}
\sum_{n} \sum_{t} h_{h p t} \cdot Q_{h n p t} \cdot Y_{h n t} \leq H_{h p}, \quad \forall h, p, \\
\sum_{i} \sum_{t} h_{n p t} \cdot Q_{n i p t} \cdot Y_{n i t} \leq H_{n p}, \quad \forall n, p, \\
\sum_{h} \sum_{t} s_{j p t} \cdot Q_{j h p t} \cdot Y_{j h t} \leq S_{j p}, \quad \forall j, p, \\
\sum_{n} \sum_{t} s_{h p t} \cdot Q_{h n p t} \cdot Y_{h n t} \leq S_{h p}, \quad \forall h, p, \\
\sum_{n} \sum_{t} s_{h p t} \cdot Q_{h n p t} \cdot Y_{h n t} \leq S_{h p}, \quad \forall n, p, \\
\sum_{k} Y_{k j t} \leq 2, \quad \forall j, t, \\
\sum_{j} Y_{j h t} \leq 1, \quad \forall h, t, \\
\sum_{h} Y_{h n t} \leq 1, \quad \forall n, t, \\
\sum_{n} Y_{n i t} \leq 1, \quad \forall i, t, \\
Y_{k j t} \leq \alpha_{k p t}, \quad \forall j, p, t, \\
Y_{k j t} \leq X_{j}, \quad \forall k, j, t, \\
Y_{j h t} \leq X_{j}, \quad \forall j, h, t, \\
Y_{j h t} \leq X_{h}, \quad \forall j, h, t, \\
Y_{h n t} \leq X_{h}, \quad \forall h, n, t, \\
Y_{h n t} \leq X_{n}, \quad \forall h, n, t, \\
Q_{h n p t}, Q_{n i p t} \geq 0, \quad \forall k, j, h, n, i, p, t,
\end{gathered}
$$

$Y_{k j t}, Y_{j h t}, Y_{h n t}, Y_{n i t}, X_{j}, X_{h}, X_{n} \in\{0,1\}, \quad \forall k, j, h, n, i, t$.

Constraints (7)-(9) ensure that the total products which are supplied by each distributor do not exceed their initial planned capacities. They ensure that the orders do not violate the capacity of hub distributors $j, h$, and $n$. Constraint (10) refers to satisfaction of the buyer's demand for each product at each time period by the last echelon of distributors. Constraints (11)-(13) control the feasibility of supply of goods in every echelon of supply chain. Constraint (11) says for each distributor at each time period if there is a trade from a supplier, then an order less than or equal to the supplier trade could be set to a nonhub distributor. Constraints (14)-(16) guarantee that the total percentages of the returned product for each product at all periods of time do not exceed the maximum acceptable percentage of each product for each distributor. Constraints (17)-(19) guarantee that the total percentages of late delivered product for each product at all periods of time do not exceed the maximum acceptable percentage of each product for each distributor. Constraint (20) controls the number of the selected trade between each hub distributor and suppliers which must be less than or equal 2 in our problem. Indeed, both suppliers require to supply products, whereas the second supplier is considered as a backup for the first supplier in the disruption condition. Constraints (21)-(23) reveal that only one trade must occur between distributors, as well as node distributors and customers. Constraints (24)-(29) control that each supplier to be selected before to be allocated a quota. It ensures that if the hub or node distributor is not selected, the right hand side is zero, and thus the trades in the left hand side could not be set. Constraints (30) and (31) indicate the given values for the decision variables in the model.

3.2. Solution Method. In this paper, a fuzzy multichoice goal programming model is utilized to solve the proposed model. In this approach, three goals (choices) are considered for each objective function. The model chooses a goal among the three choices for each function, and somehow the answer of all objective functions is close to their optimal answer. Due to the ease and accuracy in solving the model, a linearized model is proposed for this method [55]. Table 4 and constraints (20)-(28) are represented to introduce new symbols for the model and linearized model of the fuzzy three-choice goal programming method, respectively. Additionally, constraints (6)-(19) are repeated for this model.

$$
\max z t=f_{1} \mu_{1}+f_{2} \mu_{2}+f_{3} \mu_{3}+f_{4} \mu_{4}+f_{5} \mu_{5}+f_{6} \mu_{6},
$$

$$
\mu_{1} \leq 1-\frac{z_{1}-\tilde{g}_{1}}{d_{1}^{-}} u_{1}+\frac{z_{1}-\tilde{g}_{2}}{d_{2}^{-}}\left(v_{1}-u_{1}\right)+\frac{z_{1}-\tilde{g}_{3}}{d_{3}^{-}}\left(v_{2}-u_{1}\right),
$$

$$
\mu_{2} \leq 1-\frac{z_{2}-\tilde{g}_{4}}{d_{4}^{-}} u_{2}+\frac{z_{2}-\tilde{g}_{5}}{d_{5}^{-}}\left(v_{3}-u_{2}\right)+\frac{z_{2}-\tilde{g}_{6}}{d_{6}^{-}}\left(v_{4}-u_{2}\right),
$$

$$
\mu_{3} \leq 1-\frac{z_{3}-\tilde{g}_{7}}{d_{7}^{-}} u_{3}+\frac{z_{3}-\tilde{g}_{8}}{d_{7}^{-}}\left(v_{5}-u_{3}\right)+\frac{z_{3}-\tilde{g}_{9}}{d_{9}^{-}}\left(v_{6}-u_{3}\right),
$$

$\mu_{4} \leq 1-\frac{z_{4}-\widetilde{g_{10}}}{d_{10}^{-}} u_{4}+\frac{z_{4}-\widetilde{g_{11}}}{d_{11}^{-}}\left(v_{7}-u_{4}\right)+\frac{z_{4}-\widetilde{g_{12}}}{d_{12}^{-}}\left(v_{8}-u_{4}\right)$

$$
\mu_{5} \leq 1-\frac{\widetilde{g_{13}}-z_{5}}{d_{13}^{+}} u_{5}+\frac{\widetilde{g_{14}}-z_{5}}{d_{14}^{+}}\left(v_{9}-u_{5}\right)+\frac{\widetilde{g_{15}}-z_{5}}{d_{15}^{+}}\left(v_{10}-u_{5}\right),
$$


TABLE 4: The fuzzy three-choice goal programming model. Formula (32) refers to maximization of the membership function for each single objective function.

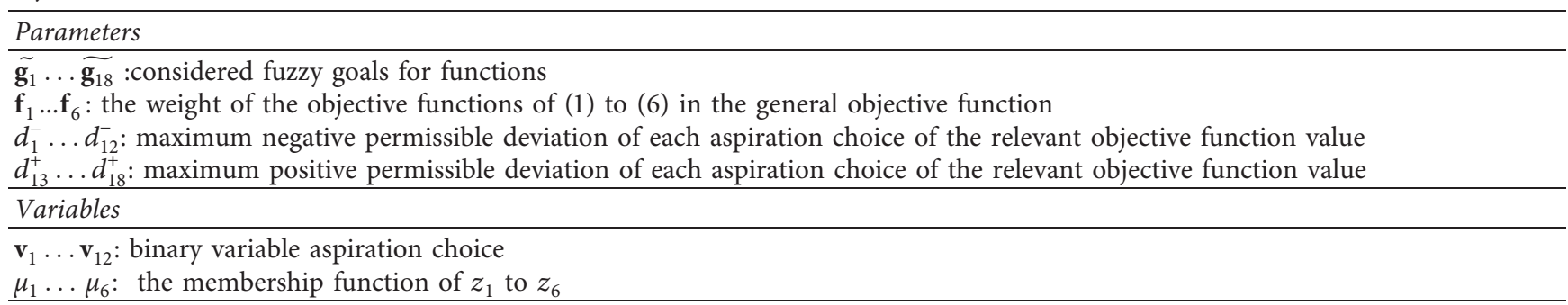

$\mu_{6} \leq 1-\frac{\widetilde{g_{16}}-z_{6}}{d_{16}^{+}} u_{6}+\frac{\widetilde{g_{17}}-z_{5}}{d_{17}^{+}}\left(v_{11}-u_{6}\right)+\frac{\widetilde{g_{18}}-z_{6}}{d_{18}^{+}}\left(v_{12}-u_{6}\right)$,

$$
\begin{gathered}
u_{1} \leq\left\{\begin{array}{c}
v_{1} \\
v_{2}
\end{array},\right. \\
u_{2} \leq\left\{\begin{array}{l}
v_{3} \\
v_{4}
\end{array},\right. \\
u_{3} \leq\left\{\begin{array}{l}
v_{5} \\
v_{6}
\end{array},\right. \\
u_{4} \leq\left\{\begin{array}{l}
v_{7} \\
v_{8}
\end{array},\right. \\
u_{5} \leq\left\{\begin{array}{l}
v_{9} \\
v_{10}
\end{array},\right. \\
u_{6} \leq\left\{\begin{array}{l}
v_{11}, \\
v_{12},
\end{array}\right. \\
u_{1} \geq v_{1}+v_{2}-1, \\
u_{2} \geq v_{3}+v_{4}-1, \\
u_{3} \geq v_{5}+v_{6}-1, \\
u_{4} \geq v_{7}+v_{8}-1, \\
u_{5} \geq v_{9}+v_{10}-1, \\
u_{6} \geq v_{11}+v_{12}-1, \\
u_{1} \cdot u_{10} \geq 0, \\
\mu_{1} \cdot v_{12} \in\{0,1\},
\end{gathered}
$$

Constraints (33)-(38) are utilized to control the membership functions of $Z_{1}$ to $Z_{6}$. They are used for minimization of $Z_{1}$ to $Z_{6}$; the maximum value of the negative permissible deviation for the objective function of any aspiration value is considered in the fraction denominator of these functions. Besides, because $Z_{5}$ and $Z_{6}$ are maximum, the maximum value of the positive deviation for the objective function of any aspiration value is applied in the denominator of the fraction. Constraint (39) is dealt with the limitation of choosing the aspiration, which demonstrates that the model can select an aspiration in each function. Constraint (40) is concerned with the linearization of the model. Constraints (41)-(43) represent the type and range of the variables.

In Section 4, a real numerical case study is considered for this model.

\section{Numerical Results}

In this section, a numerical case study is surveyed for asthma-specific medicines. Accordingly, the real data of Cobel Darou pharmaceutical company were collected in 2019. Also, it is noted that the $R$ optimization solver is utilized to solve this real example. The value of parameters is specified as follows. The exact values are represented for the demand and probability of supplier disruption in $\mathrm{Ta}$ ble 5 and Table 6 , respectively. It would be valuable to denote that the buyer of pharmacies is located in 4 cities of Iran comprising Tehran, Esfahan, Ahvaz, and Mashhad which is demonstrated in Figure 2. The demands for the investigated centers are considered as 5 of the highest level of applicants in each city, which are indicated to be expressed for cities with the indexes 1 to 20, respectively. The value of other parameters is declared on the base of the interval in Table 7 due to improving expression in the paper. The whole exact value of parameters is in the introduced intervals, and generally, the value has been obtained for the parameters of $q$ and $\lambda$ using the well-known AHP methods [56].

It is obvious that there are 2 suppliers for the selected pharmacies, with the names of AstraZeneca and GSK, which are introduced by the indexes $k=1$ and $k=2$ in the model, respectively. In addition, indexes $p=1$ to $p=5$ are devoted to the pharmacies with the names of Pulmicort, Symbicort, Flixotide, Seretide, and Rhinocort, respectively.

Furthermore, the values of the first choice are considered for aspirations as the optimal value of the single function, and consequently, the second and third choices are considered for aspirations with 10 and $20 \%$ variations, respectively. It is done in comparison with the optimal value (increase for minimization and decrease for maximization functions). The maximum negative and positive deviations for each choice and the weight of the objective functions are also determined by experts.

The presented model has been solved based on these parameters. Table 8 gives the results of the objective functions for the numerical example.

The obtained values are considered for objective function as rational results. These values are proportionate to the expectation level with the emphasis on actual parameters. In 
TABLE 5: The values of demands.

\begin{tabular}{|c|c|c|c|c|c|c|}
\hline$D_{\text {ipt }}$ & & $p=1$ & $p=2$ & $p=3$ & $p=4$ & $p=5$ \\
\hline \multirow{4}{*}{$i=1$} & $t=1$ & 570 & 640 & 120 & 346 & 90 \\
\hline & $t=2$ & 1001 & 720 & 456 & 221 & 54 \\
\hline & $t=3$ & 375 & 370 & 0 & 408 & 60 \\
\hline & $t=4$ & 367 & 10 & 15 & 25 & 5 \\
\hline \multirow{4}{*}{$i=2$} & $t=1$ & 484 & 60 & 123 & 423 & 110 \\
\hline & $t=2$ & 1965 & 60 & 310 & 1046 & 68 \\
\hline & $t=3$ & 1687 & 115 & 10 & 890 & 0 \\
\hline & $t=4$ & 236 & 130 & 80 & 75 & 50 \\
\hline \multirow{4}{*}{$i=3$} & $t=1$ & 352 & 128 & 651 & 780 & 15 \\
\hline & $t=2$ & 2005 & 1328 & 450 & 654 & 87 \\
\hline & $t=3$ & 426 & 147 & 12 & 38 & 26 \\
\hline & $t=4$ & 190 & 0 & 30 & 580 & 0 \\
\hline \multirow{4}{*}{$i=4$} & $t=1$ & 269 & 56 & 98 & 69 & 52 \\
\hline & $t=2$ & 706 & 244 & 53 & 471 & 22 \\
\hline & $t=3$ & 54 & 10 & 0 & 30 & 10 \\
\hline & $t=4$ & 10 & 168 & 0 & 54 & 1 \\
\hline \multirow{4}{*}{$i=5$} & $t=1$ & 189 & 120 & 94 & 39 & 0 \\
\hline & $t=2$ & 1007 & 23 & 152 & 430 & 0 \\
\hline & $t=3$ & 52 & 0 & 26 & 15 & 164 \\
\hline & $t=4$ & 67 & 0 & 11 & 25 & 52 \\
\hline \multirow{4}{*}{$i=6$} & $t=1$ & 406 & 357 & 83 & 124 & 351 \\
\hline & $t=2$ & 0 & 401 & 112 & 131 & 25 \\
\hline & $t=3$ & 18 & 1314 & 12 & 1807 & 173 \\
\hline & $t=4$ & 8 & 0 & 4 & 110 & 0 \\
\hline \multirow{4}{*}{$i=7$} & $t=1$ & 127 & 11 & 87 & 250 & 56 \\
\hline & $t=2$ & 21 & 29 & 2 & 469 & 32 \\
\hline & $t=3$ & 1 & 79 & 23 & 16 & 5 \\
\hline & $t=4$ & 36 & 163 & 0 & 123 & 1 \\
\hline \multirow{4}{*}{$i=8$} & $t=1$ & 298 & 0 & 36 & 14 & 169 \\
\hline & $t=2$ & 47 & 101 & 149 & 0 & 42 \\
\hline & $t=3$ & 17 & 22 & 11 & 0 & 0 \\
\hline & $t=4$ & 136 & 0 & 170 & 0 & 0 \\
\hline \multirow{4}{*}{$i=9$} & $t=1$ & 230 & 36 & 1113 & 14 & 75 \\
\hline & $t=2$ & 126 & 0 & 26 & 159 & 41 \\
\hline & $t=3$ & 1008 & 85 & 0 & 21 & 7 \\
\hline & $t=4$ & 13 & 13 & 0 & 5 & 6 \\
\hline \multirow{4}{*}{$i=10$} & $t=1$ & 552 & 11 & 0 & 39 & 63 \\
\hline & $t=2$ & 123 & 25 & 0 & 137 & 1 \\
\hline & $t=3$ & 63 & 140 & 0 & 11 & 1 \\
\hline & $t=4$ & 20 & 63 & 102 & 1 & 0 \\
\hline \multirow{4}{*}{$i=11$} & $t=1$ & 363 & 160 & 498 & 260 & 1109 \\
\hline & $t=2$ & 106 & 350 & 52 & 11 & 114 \\
\hline & $t=3$ & 106 & 113 & 110 & 0 & 15 \\
\hline & $t=4$ & 98 & 39 & 110 & 231 & 18 \\
\hline \multirow{4}{*}{$i=12$} & $t=1$ & 630 & 1100 & 98 & 469 & 0 \\
\hline & $t=2$ & 117 & 1100 & 174 & 47 & 112 \\
\hline & $t=3$ & 12 & 0 & 24 & 58 & 0 \\
\hline & $t=4$ & 69 & 1100 & 16 & 132 & 112 \\
\hline \multirow{4}{*}{$i=13$} & $t=1$ & 392 & 99 & 613 & 26 & 95 \\
\hline & $t=2$ & 20 & 36 & 59 & 2 & 41 \\
\hline & $t=3$ & 3 & 48 & 7 & 26 & 0 \\
\hline & $t=4$ & 11 & 5 & 7 & 2 & 59 \\
\hline \multirow{4}{*}{$i=14$} & $t=1$ & 123 & 56 & 635 & 98 & 1115 \\
\hline & $t=2$ & 4 & 169 & 15 & 135 & 52 \\
\hline & $t=3$ & 46 & 110 & 12 & 135 & 0 \\
\hline & $t=4$ & 26 & 0 & 19 & 0 & 569 \\
\hline
\end{tabular}


TABle 5: Continued.

\begin{tabular}{|c|c|c|c|c|c|c|}
\hline$D_{\text {ipt }}$ & & $p=1$ & $p=2$ & $p=3$ & $p=4$ & $p=5$ \\
\hline \multirow{4}{*}{$i=15$} & $t=1$ & 1405 & 690 & 120 & 75 & 0 \\
\hline & $t=2$ & 55 & 2 & 20 & 25 & 101 \\
\hline & $t=3$ & 236 & 3 & 2 & 0 & 141 \\
\hline & $t=4$ & 10 & 95 & 46 & 12 & 10 \\
\hline \multirow{4}{*}{$i=16$} & $t=1$ & 460 & 15 & 300 & 169 & 75 \\
\hline & $t=2$ & 145 & 10 & 100 & 115 & 115 \\
\hline & $t=3$ & 84 & 52 & 250 & 50 & 77 \\
\hline & $t=4$ & 41 & 63 & 22 & 59 & 55 \\
\hline \multirow{4}{*}{$i=17$} & $t=1$ & 290 & 504 & 605 & 130 & 20 \\
\hline & $t=2$ & 1296 & 575 & 123 & 102 & 109 \\
\hline & $t=3$ & 232 & 325 & 457 & 25 & 64 \\
\hline & $t=4$ & 85 & 240 & 110 & 90 & 74 \\
\hline \multirow{4}{*}{$i=18$} & $t=1$ & 40 & 500 & 20 & 134 & 23 \\
\hline & $t=2$ & 818 & 250 & 17 & 79 & 125 \\
\hline & $t=3$ & 196 & 215 & 68 & 230 & 513 \\
\hline & $t=4$ & 70 & 100 & 105 & 300 & 420 \\
\hline \multirow{4}{*}{$i=19$} & $t=1$ & 142 & 235 & 500 & 151 & 495 \\
\hline & $t=2$ & 210 & 320 & 120 & 100 & 858 \\
\hline & $t=3$ & 520 & 300 & 407 & 72 & 21 \\
\hline & $t=4$ & 400 & 326 & 98 & 510 & 600 \\
\hline \multirow{4}{*}{$i=20$} & $t=1$ & 190 & 440 & 105 & 410 & 480 \\
\hline & $t=2$ & 440 & 4 & 120 & 100 & 80 \\
\hline & $t=3$ & 193 & 80 & 220 & 25 & 110 \\
\hline & $t=4$ & 770 & 80 & 540 & 312 & 100 \\
\hline
\end{tabular}

TABLE 6: The values of disruption of suppliers.

\begin{tabular}{ll}
\hline $\mathbf{R}_{1}$ & $5.87 \%$ \\
$\mathbf{R}_{2}$ & $3.61 \%$ \\
\hline
\end{tabular}

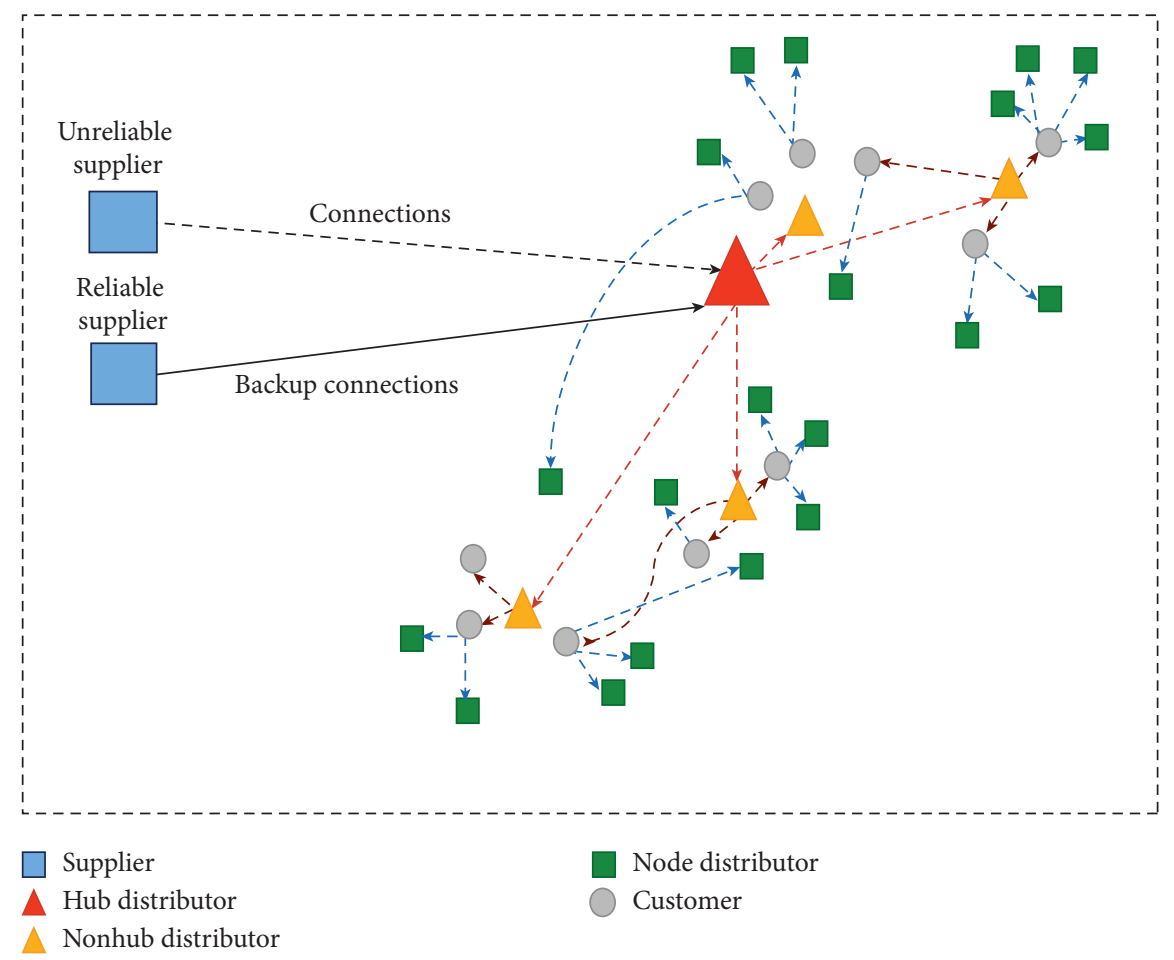

FIgURE 2: The case study's network topology. 
TABLE 7: The intervals of parameters.

\begin{tabular}{|c|c|}
\hline TS & {$[50,150]$} \\
\hline$W$ & {$[5000,10000]$} \\
\hline$C$ & {$[200,850]$} \\
\hline$C C$ & {$[20,50]$} \\
\hline$h$ & {$[0,0.1]$} \\
\hline$s$ & {$[0.01,0.25]$} \\
\hline$H$ & {$[0.1,0.2]$} \\
\hline$S$ & {$[0.1,0.4]$} \\
\hline$F$ & {$[4000,10000]$} \\
\hline$q$ & {$[3,8]$} \\
\hline$L$ & {$\left[5 \times 10^{4}, 9 \times 10^{5}\right]$} \\
\hline$\lambda$ & {$[2,9]$} \\
\hline$\beta$ & $35 \%$ \\
\hline$\alpha$ & $\in\{0,1\}$ \\
\hline
\end{tabular}

TABLE 8: The membership functions of a numerical example.

\begin{tabular}{ll}
\hline $\boldsymbol{\mu}_{1}$ & 0.91 \\
$\boldsymbol{\mu}_{2}$ & 0.89 \\
$\boldsymbol{\mu}_{3}$ & 0.72 \\
$\boldsymbol{\mu}_{4}$ & 0.67 \\
$\boldsymbol{\mu}_{5}$ & 0.80 \\
$\boldsymbol{\mu}_{6}$ & 0.81 \\
\hline
\end{tabular}

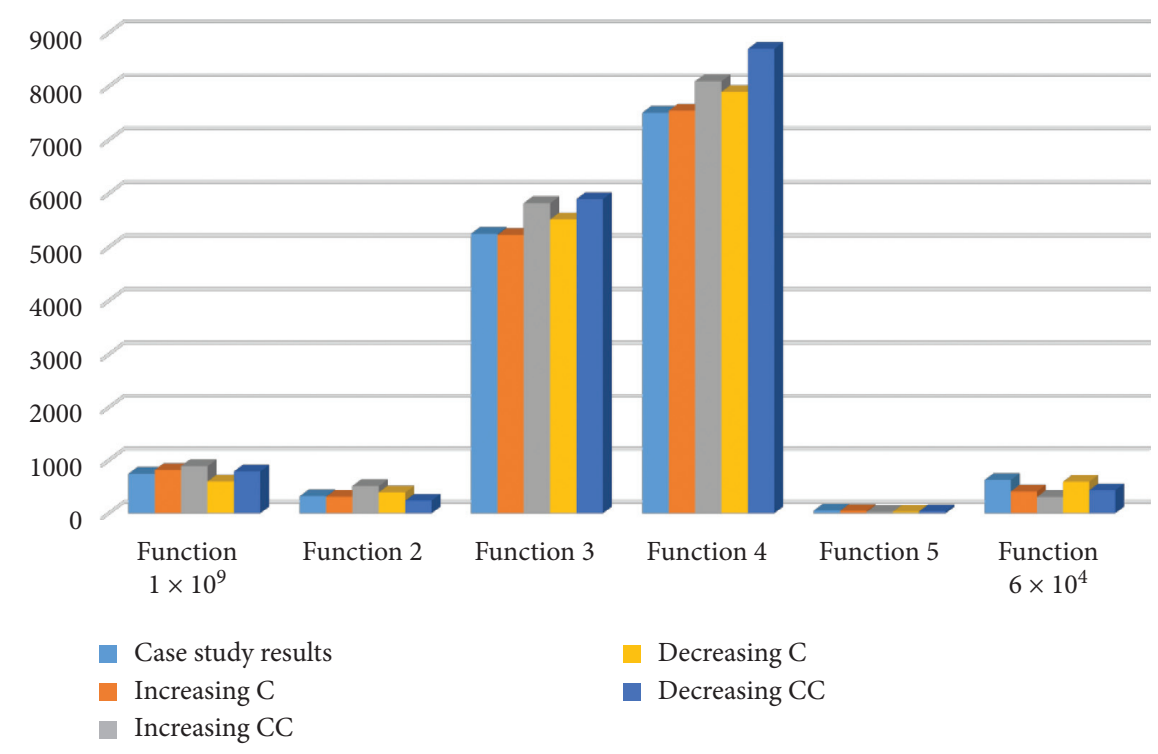

FIgURE 3: The results of function with alteration values of $C$ and $C C$ in four examples.

the next section, the sensitivity analysis is investigated for the case study by changing the value of some parameters.

\section{Sensitivity Analysis}

In this section, an attempt has been performed to prove the authority of the presented model. Therefore, it is essential to analyze the model by changing the values of some parameters. The alternations are addressed in the following paragraphs, and their results are depicted by the diagram. To develop a sensitivity analysis, the first step has been associated with changing the interval of values of $C$ and $C C$. The attained consequences are shown in Figure 3. The next step is focused on changing the range of $h$ and $q$. The outcomes are demonstrated in Figure 4. In the last step, the values of $q$ and $R$ are changed and their results are indicated in Figure 5 .

In these examples, it is obvious that the value of functions proportionally alters with the fluctuation of parameters. Indeed, all of them correctly respond to any alterations. Increment and decrement of the values of $C$ and $C C$ have virtually effect on all function. According to the formulas of the objective functions, increasing or decreasing the values of $C$ and $C C$ directly affects the first and second objective functions, respectively, and indirectly affects other 


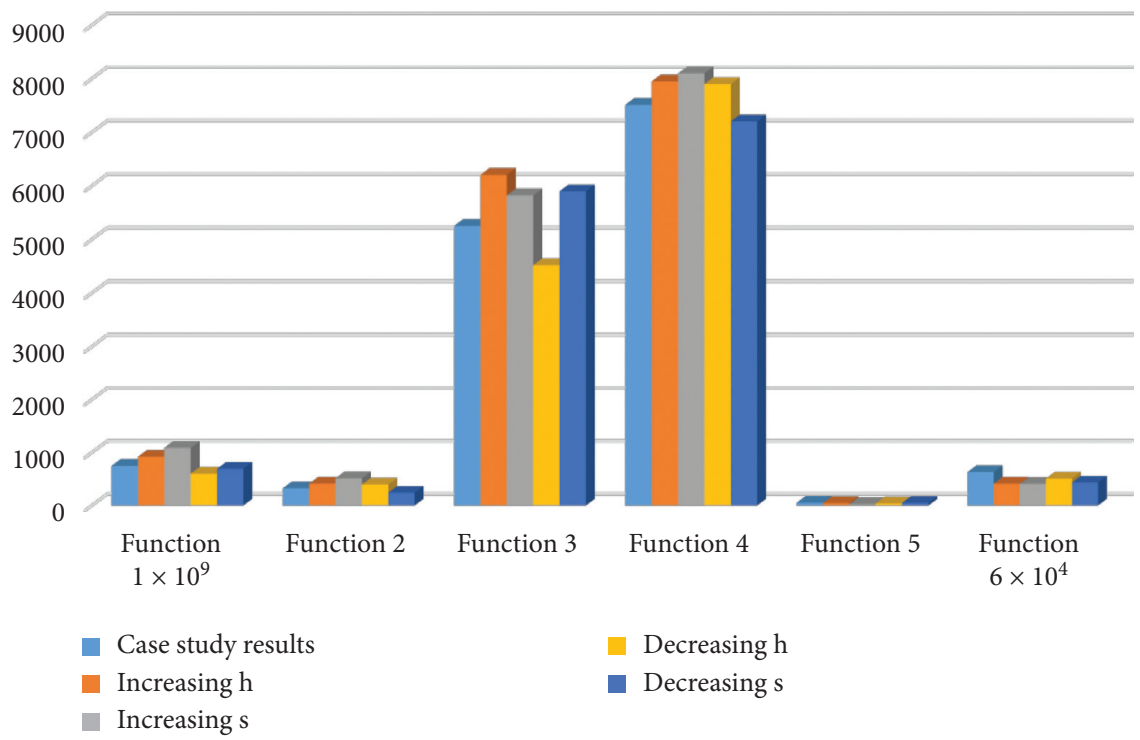

FIgURE 4: The results of function with alteration values of $h$ and $s$ in four examples.

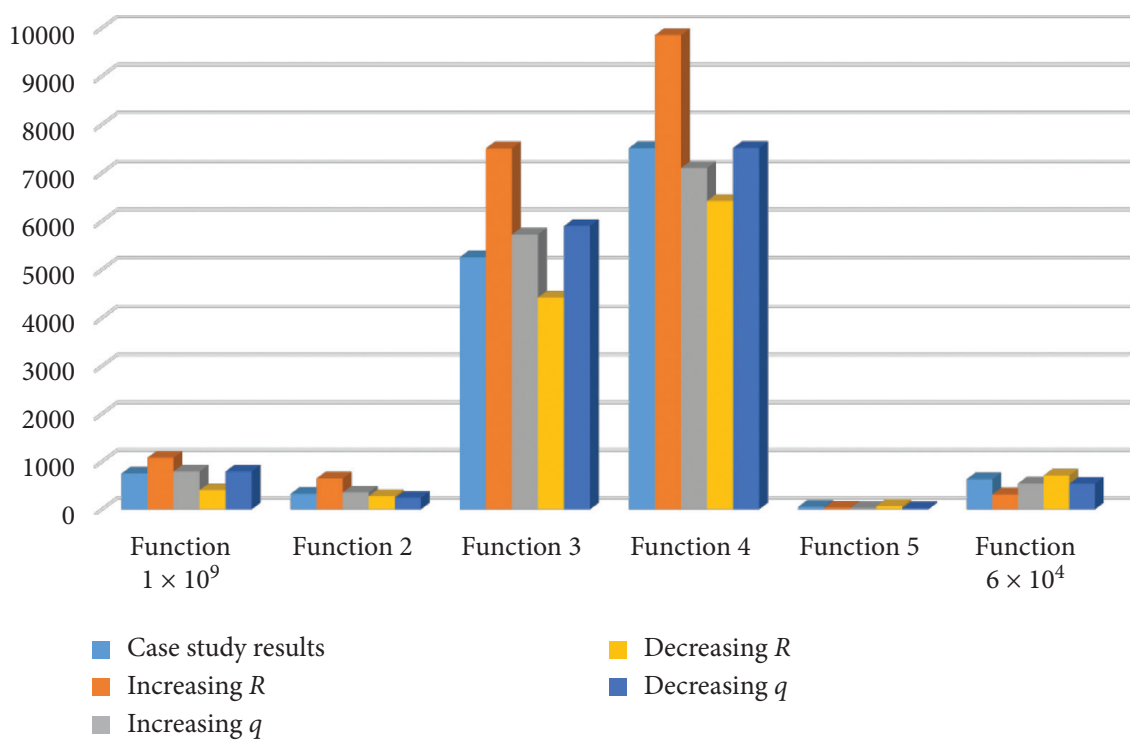

Figure 5: The results of function with alteration values of $R$ and $q$ in four examples.

functions. Increasing or decreasing the value of $C$ has not had such an effect on the objective functions, while increasing or decreasing the value of $C C$ has a more significant effect on the objective functions than $C$. However, this effect is not to improve the performance of the functions, Because objective functions 1 to 4 are of type Min and objective functions 5 and 6 are of type Max and by increasing the value of $C C$, the values of objective functions 1 to 4 increased and the values of objective functions 5 and 6 decreased, and by decreasing the value of $C C$, only the objective function 2 improved slightly in terms of performance. Furthermore, variations in the values of $h$ and $s$ have expected reactions, and according to the above analysis, we can conclude that the values of the objective functions improved collectively only through decreasing the value of $h$. Finally, increasing and decreasing the value of $q$ have not had such an effect on the objective functions. However, the most important repercussion is reached by variation in $\mathrm{R}$. The functionality of all functions improves by reducing the value of $R$, and by increasing the values of $R$, all functions become more undesirable than the optimal results. These results demonstrate the magnitude of surveying the disruptive conditions in supply chain management. The dynamic and inaccurate nature of the quantity and quality of manufactured products has created a high degree of uncertainty and risk in supply chains. Therefore, it is necessary to identify and formulate these kinds of risks. Additionally, the uncertain mode of supplier disruption probability brings the model closer to the real-world model. Eventually, it is vivid that the validity of the modeling process is proved through this analysis. 


\section{Conclusions and Further Research Ideas}

In this paper, the hub location-allocation problem was studied to optimize six objective functions such as minimization of transaction costs, delayed goods, returned goods, and total fixed cost. Medicine unreliability problem is one of the most important issues in health supply chain management. This study tries to help the decision makers in health management institutions to optimize the distribution activities. It is worth noting that the parameters of supplier disruption probabilities were considered as uncertain parameters. An authentic case study was exerted for health supply chain management, and then it was investigated via the fuzzy multichoice goal programming method in $R$ optimization solver. According to these results, it is certified that the introduced model is proper and adaptable for problems in real-world situations. Also, sensitivity analyses were considered with respect to variations in parameters, and the importance of the $R$ parameter is clearly shown in a way that if the risks and disruptions in the supply chain are properly identified and addressed for reducing it, all the expected goals in the supply chain management can be achieved, which generally includes cost reduction, minimization of expected percentages of delayed and returned goods, and increase customer satisfaction. This evaluation procedure confirms the significance and validity of the recommended model.

Some limitations of the study are the traffic situation consideration during the distribution time which affect of the delayed products. The truck load layout design could be considered for the last echelon. The vehicle types and capacities could improve the problem design.

As further research studies in this area, it is possible to use multiobjective metaheuristic algorithms and multicriteria decision-making methods for the selection of suppliers and distributors. In addition, various types of supply risks can also be considered for analyzing the process. Other extensions can expand the model and represent other benefits of a supply chain for the achievement of a win-win position.

\section{Data Availability}

The data used to support the study are available from the corresponding author upon request.

\section{Conflicts of Interest}

The authors declare that they have no conflicts of interest.

\section{References}

[1] N. Rego, J. Claro, and J. Pinho de Sousa, "A hybrid approach for integrated healthcare cooperative purchasing and supply chain configuration," Health Care Management Science, vol. 17, no. 4, pp. 303-320, 2014.

[2] N. Habidin, N. A. Shazali, M. Ithnin, Z. Zainol, N. Salleh Hudin, and W. S. W. Mustaffa, "A review of supply chain innovation and healthcare performance in healthcare industry," Performance in Supply Chain Management (SCM), vol. 35, pp. 195-200, 2015.

[3] R. Uthayakumar and S. Priyan, "Pharmaceutical supply chain and inventory management strategies: optimization for a pharmaceutical company and a hospital," Operations Research for Health Care, vol. 2, no. 3, pp. 52-64, 2013.

[4] C. W. Craighead, J. Blackhurst, M. J. Rungtusanatham, and R. B. Handfield, "The severity of supply chain disruptions: design characteristics and mitigation capabilities," Decision Sciences, vol. 38, no. 1, pp. 131-156, 2007.

[5] M. Taghi, A. Nedjati, and R. Kazemi, "Solving health care facility location problems with new heuristic algorithm method," International Journal Of Modeling and Optimization, vol. 3, pp. 12-14, 2013.

[6] N. Agami, M. Saleh, and M. Rasmy, "Supply chain performance measurement approaches: review and classification," Journal of Organizational Management Studies, vol. 2012, Article ID 872753, 20 pages, 2012.

[7] N. Privett and D. Gonsalvez, "The top ten global health supply chain issues: perspectives from the field," Operations Research for Health Care, vol. 3, no. 4, pp. 226-230, 2014.

[8] J.-M. Lawrence, N. U. Ibne Hossain, R. Jaradat, and M. Hamilton, "Leveraging a Bayesian network approach to model and analyze supplier vulnerability to severe weather risk: a case study of the U.S. pharmaceutical supply chain following Hurricane Maria," International Journal of Disaster Risk Reduction, vol. 49, Article ID 101607, 2020.

[9] F. Sabouhi, M. S. Pishvaee, and M. S. Jabalameli, "Resilient supply chain design under operational and disruption risks considering quantity discount: a case study of pharmaceutical supply chain," Computers \& Industrial Engineering, vol. 126, pp. 657-672, 2018.

[10] H. Abolghasemi, M. H. Radfar, M. Tabatabaee, N. S. HosseiniDivkolayee, and F. M. Burkle, "Revisiting blood transfusion preparedness: experience from the Bam earthquake response," Prehospital and Disaster Medicine, vol. 23, no. 5, pp. 391-394, 2008.

[11] N. Aydin and A. Murat, "A swarm intelligence based sample average approximation algorithm for the capacitated reliable facility location problem," International Journal of Production Economics, vol. 145, no. 1, pp. 173-183, 2013.

[12] P. Peng, L. V. Snyder, A. Lim, and Z. Liu, "Reliable logistics networks design with facility disruptions," Transportation Research Part B: Methodological, vol. 45, no. 8, pp. 1190-1211, 2011.

[13] WHO, Corona Virus Disease (COVID-19) Outbreak Situation. 1 June 2020, WHO, Geneva, Switzerland, 2020, https://www. who.int/emergencies/diseases/novel-coronavirus-2019.

[14] B. Fahimnia, A. Jabbarzadeh, A. Ghavamifar, and M. Bell, "Supply chain design for efficient and effective blood supply in disasters," International Journal of Production Economics, vol. 183, pp. 700-709, 2017.

[15] P. Bogaert, T. Bochenek, A. Prokop, and A. Pilc, "A qualitative approach to a better understanding of the problems underlying drug shortages, as viewed from Belgian, French and the European union's perspectives," PLoS One, vol. 10, no. 5, Article ID e0125691, 2015.

[16] K. Pauwels, S. Simoens, M. Casteels, and I. Huys, "Insights into European drug shortages: a survey of hospital pharmacists," PLoS One, vol. 10, no. 3, Article ID e0119322, 2015.

[17] J. De Vries and R. Huijsman, "Supply chain management in health services: an overview," Supply Chain Management: An International Journal, vol. 16, no. 3, pp. 159-165, 2011. 
[18] S. PrasannaVenkatesan and M. Goh, "Multi-objective supplier selection and order allocation under disruption risk," Transportation Research Part E: Logistics and Transportation Review, vol. 95, pp. 124-142, 2016.

[19] B. Hamdan and A. Diabat, "Robust design of blood supply chains under risk of disruptions using Lagrangian relaxation," Transportation Research Part E: Logistics and Transportation Review, vol. 134, Article ID 101764, 2020.

[20] T.-M. Choi, "Innovative "bring-service-near-your-home" operations under corona-virus (COVID-19/SARS-CoV-2) outbreak: can logistics become the messiah?" in Transportation Research Part E: Logistics and Transportation ReviewElsevier, Amsterdam, Netherlands, 2020.

[21] D. Ivanov, "Predicting the impacts of epidemic outbreaks on global supply chains: a simulation-based analysis on the coronavirus outbreak (COVID-19/SARS-CoV-2) case," Transportation Research Part E: Logistics and Transportation Review, vol. 136, Article ID 101922, 2020.

[22] K. Govindan, H. Mina, and B. Alavi, "A decision support system for demand management in healthcare supply chains considering the epidemic outbreaks: a case study of coronavirus disease 2019 (COVID-19)," Transportation Research Part E: Logistics and Transportation Review, vol. 138, Article ID 101967, 2020.

[23] O. Aptel and H. Pourjalali, "Improving activities and decreasing costs of logistics in hospitals: a comparison of U.S. and French hospitals," The International Journal of Accounting, vol. 36, no. 1, pp. 65-90, 2001.

[24] P. Harper, A. K. Shahani, J. E. Gallagher, and C. Bowie, "Planning health services with explicit geographical considerations: a stochastic location-allocation approach," Omega, vol. 33, no. 2, pp. 141-152, 2005.

[25] D. A. Jacobs, M. N. Silan, and B. A. Clemson, “An analysis of alternative locations and service areas of American red cross blood facilities," Interfaces, vol. 26, no. 3, pp. 40-50, 1996.

[26] B. Zahiri, R. Tavakkoli-Moghaddam, and M. S. Pishvaee, "A robust possibilistic programming approach to multi-period location-allocation of organ transplant centers under uncertainty," Computers \& Industrial Engineering, vol. 74, pp. 139-148, 2014.

[27] T. Ünlüyurt and Y. Tunçer, "Estimating the performance of emergency medical service location models via discrete event simulation," Computers \& Industrial Engineering, vol. 102, pp. 467-475, 2016.

[28] S. Khodaparasti, M. E. Bruni, P. Beraldi, H. R. Maleki, and S. Jahedi, "A multi-period location-allocation model for nursing home network planning under uncertainty," Operations Research for Health Care, vol. 18, pp. 4-15, 2018.

[29] S.-U. Rahman and D. K. Smith, "Use of location-allocation models in health service development planning in developing nations," European Journal of Operational Research, vol. 123, no. 3, pp. 437-452, 2000.

[30] M. J. Hodgson and S. K. Jacobsen, "A hierarchical locationallocation model with travel based on expected referral distances," Annals of Operations Research, vol. 167, no. 1, pp. 271-286, 2008.

[31] A. M. Mestre, M. D. Oliveira, and A. P. Barbosa-Póvoa, "Location-allocation approaches for hospital network planning under uncertainty," European Journal of Operational Research, vol. 240, no. 3, pp. 791-806, 2015.

[32] S. Hovav and D. Tsadikovich, "A network flow model for inventory management and distribution of influenza vaccines through a healthcare supply chain," Operations Research for Health Care, vol. 5, pp. 49-62, 2015.
[33] A. Elalouf, S. Hovav, D. Tsadikovich, and L. Yedidsion, "Minimizing operational costs by restructuring the blood sample collection chain," Operations Research for Health Care, vol. 7, pp. 81-93, 2015.

[34] P. Chaiwuttisak, H. Smith, Y. Wu, C. Potts, T. Sakuldamrongpanich, and S. Pathomsiri, "Location of lowcost blood collection and distribution centres in Thailand," Operations Research for Health Care, vol. 9, pp. 7-15, 2016.

[35] A. S. Safaei, F. Heidarpoor, and M. M. Paydar, "A novel mathematical model for group purchasing in healthcare," Operations Research for Health Care, vol. 15, pp. 82-90, 2017.

[36] L. Wang, H. Shi, and L. Gan, "Healthcare facility locationallocation optimization for China's developing cities utilizing a multi-objective decision support approach," Sustainability, vol. 10, no. 12, 2018.

[37] F. Barzinpour, M. Maleki Rastaghi, and M. S. Pishvaee, "A multi-objective hierarchical location-allocation model for the healthcare network design considering a referral system," International Journal of Engineering, vol. 31, no. 2, pp. 365373, 2018, http://www.ije.ir/article_73129_ 7191547c1a8311e212712e9f8632ddb9.pdf.

[38] Z. Drezner, "Heuristic solution methods for two location problems with unreliable facilities," Journal of the Operational Research Society, vol. 38, no. 6, pp. 509-514, 1987.

[39] C. Bode, S. M. Wagner, K. J. Petersen, and L. M. Ellram, "Understanding responses to supply chain disruptions: insights from information processing and resource dependence perspectives," Academy of Management Journal, vol. 54, no. 4, pp. 833-856, 2011.

[40] Y. Sheffi and J. B. Rice, "A supply chain view of the resilient enterprise," MIT Sloan Management Review, vol. 47, no. 1, p. $41,2005$.

[41] C. S. Tang, "Robust strategies for mitigating supply chain disruptions," International Journal of Logistics Research and Applications, vol. 9, no. 1, pp. 33-45, 2006.

[42] U. Jüttner and S. Maklan, "Supply chain resilience in the global financial crisis: an empirical study," Supply Chain Management: An International Journal, vol. 16, no. 4, pp. 246-259, 2011.

[43] S. Y. Teoh and H. S. Zadeh, "Strategic resilience management model: complex enterprise systems upgrade implementation," Pacific Asia Journal of the Association for Information Systemss, vol. 103, 2013.

[44] H.-C. Pfohl, H. Köhler, and D. Thomas, "State of the art in supply chain risk management research: empirical and conceptual findings and a roadmap for the implementation in practice," Logistics Research, vol. 2, no. 1, pp. 33-44, 2010.

[45] D. Vlachos, E. Iakovou, K. Papapanagiotou, and D. Partsch, "Building robust supply chains by reducing vulnerability and improving resilience," International Journal of Agile Systems and Management, vol. 5, no. 1, pp. 59-81, 2012.

[46] H. Peck, "Reconciling supply chain vulnerability, risk and supply chain management," International Journal of Logistics Research and Applications, vol. 9, no. 2, pp. 127-142, 2006.

[47] T. Cui, Y. Ouyang, and Z.-J. M. Shen, "Reliable facility location design under the risk of disruptions," Operations Research, vol. 58, no. 4, pp. 998-1011, 2010.

[48] Z.-J. M. Shen, R. L. Zhan, and J. Zhang, "The reliable facility location problem: formulations, heuristics, and approximation algorithms," INFORMS Journal on Computing, vol. 23, no. 3, pp. 470-482, 2011, https://EconPapers.repec.org/ RePEc:inm:orijoc:v:23:y:2011:i:3.

[49] D. Shishebori and A. Yousefi Babadi, "Robust and reliable medical services network design under uncertain 
environment and system disruptions," Transportation Research Part E: Logistics and Transportation Review, vol. 77, pp. 268-288, 2015.

[50] S. An, N. Cui, Y. Bai, W. Xie, M. Chen, and Y. Ouyang, "Reliable emergency service facility location under facility disruption, en-route congestion and in-facility queuing," Transportation Research Part E: Logistics and Transportation Review, vol. 82, pp. 199-216, 2015.

[51] N. Zarrinpoor, M. S. Fallahnezhad, and M. S. Pishvaee, "Design of a reliable hierarchical location-allocation model under disruptions for health service networks: a two-stage robust approach," Computers \& Industrial Engineering, vol. 109, pp. 130-150, 2017.

[52] A. Diabat, A. Jabbarzadeh, and A. Khosrojerdi, "A perishable product supply chain network design problem with reliability and disruption considerations," International Journal of Production Economics, vol. 212, pp. 125-138, 2019.

[53] M. Fattahi and K. Govindan, "A multi-stage stochastic program for the sustainable design of biofuel supply chain networks under biomass supply uncertainty and disruption risk: a real-life case study," Transportation Research Part E: Logistics and Transportation Review, vol. 118, pp. 534-567, 2018.

[54] N. Haghjoo, R. Tavakkoli-Moghaddam, H. ShahmoradiMoghadam, and Y. Rahimi, "Reliable blood supply chain network design with facility disruption: a real-world application," Engineering Applications of Artificial Intelligence, vol. 90, Article ID 103493, 2020

[55] B. Bankian-Tabrizi, K. Shahanaghi, and M. Saeed Jabalameli, "Fuzzy multi-choice goal programming," Applied Mathematical Modelling, vol. 36, no. 4, pp. 1415-1420, 2012.

[56] C. Kubat and B. Yuce, "hybrid intelligent approach for supply chain management system," Journal of Intelligent Manufacturing, vol. 23, no. 4, pp. 1237-1244, 2012. 